\title{
Políticas para educaÇáo de JOVENS E ADULTOS NO BRASIL: A PRODUÇÁO DA ÁREA NOS ANOS DE 2011 E 2012 VEICULADAS NA ANPED
}

\begin{abstract}
Regina M. B. de Araújo
Doutora em educaçáo pela Unicamp, professora adjunta do Departamento de Educação e do Programa de Pós-graduação em Educação da Universidade Federal de Ouro Preto, pesquisadora pela Fapemig e CNPq. Ufop
\end{abstract} Angelita A. A. Freitas
Graduada em história, mestranda do Programa de Pós-graduaçáo em Educaçáo da Universidade Federal
de Ouro Preto. Ufop

Célia Maria F. Nunes Doutora em educação pela PUC-RJ, vice-reitora da Ufop, professora adjunta do Departamento de Educação e do Programa de Pós-graduação em Educação da Universidade Federal de Ouro Preto, pesquisadora pela Fapemig e CNPq. Ufop

José Rubens Lima Jardilino

Doutor em educação, vice-coordenador e professor do Programa de Pós-graduação em Educação da Ufop, professor adjunto do Departamento de Educação da Universidade Federal de Ouro Preto, pesquisador pela Fapemig e CNPq, membro do Comitê Científico da Anped. Ufop

Grupo de Pesquisa e Estudos sobre Formação e Profissão Docentes (Foprofi) Agência Financiadora: Fapemig

Resumo: Este artigo visa apresentar o balanço da produçáo científica acerca das políticas públicas para a educaçáo de jovens e adultos (EJA) apresentada no Grupo de Trabalho Educação de Pessoas Jovens e Adultos, denominado também como GT ı8, da Associação Nacional de Pós-Graduação e Pesquisa em Educação (Anped), nos anos de 201 I e 2012. Para realizaçáo deste trabalho, foram consultados todos os resumos dos textos submetidos ao GT I8, no período mencionado, totalizando 32 produçóes e foi feita leitura na íntegra dos trabalhos considerados com potencial para esta pesquisa. Algumas pesquisas foram empreendidas com o intuito de mapear as políticas públicas para educação de jovens e adultos no Brasil. Os trabalhos denominados Estado da Arte e Estado do Conhecimento têm sido recorrentes em várias áreas do conhecimento. Dentre eles destacamos os de Ventura (2008), Santos e Viana (20II) e Araújo e Jardilino (20II). O artigo que ora se apresenta se insere neste tipo de pesquisa, dada a sua importância e relevância. A partir dos trabalhos apresentados, percebem-se algumas continuidades no que foi constatado nas pesquisas anteriores, como também algumas alteraçóes. Chama a atenção o número reduzido de pesquisas apresentadas na Anped, GT i8, que trataram do financiamento da educaçáo de jovens e adultos. Percebeu-se também uma continuidade quanto ao aumento da quantidade de produçóes sobre os programas federais para a EJA, especialmente o Proeja. A pesquisa constata um interesse crescente da academia 
por compreender, analisar e até mesmo intervir neste meio, buscando melhorias para as políticas de oferta da educação de jovens e adultos em nosso país.

Palavras-chave: Educação de jovens e adultos. Políticas públicas. Formação docente.

Aвstract: This article presents an take stock of scientific production on public policies for the education of youth and adults ( EJA ) presented in the working group "education of the youth and adults", in the National Association of Graduate Studies and Research in Education (Anped), in the years 20II and 20I2. For this study, were consulted all the summaries of the texts submitted to the working group referred, in mentioned period, totaling 32 productions and reading was taken in full of works considered the potential for this research. Some research has been undertaken in order to map the public policies for education of youth and adults in Brazil. The work called state of the art and state of knowledge have been recurrent in various fields of knowledge. Among them include Ventura (2008 ), Santos and Viana (20I I ) and Araujo and Jardilino (20I I ). The article presented here is included in this type of research, given its importance and relevance. From the work presented, realize yourself some continuities in what was found in previous research, as well as some changes . Note the reduced number of research presented in Anped,working group I8, which dealt with the financing of youth and adult education. Also noticed a continuity in increasing the amount of production on federal programs for adult education, especially "PROEJA". The survey finds a growing interest by the academy understand, analyze and even intervene in this environment, seeking improvements to policies offer adult and youth education in our country .

KeYwords: Education of the youth and adults. Public policy. Teacher training .

Introdução

Este artigo visa apresentar o balanço da produção científica acerca das políticas públicas para a educação de jovens e adultos (EJA) apresentada no Grupo de Trabalho Educação de Pessoas Jovens e Adultos, denominado também como GT i8, da Associação Nacional de Pós-Graduação e Pesquisa em Educação (Anped), nos anos de 201 I e 20I2. ${ }^{\mathrm{I}}$

Para realizaçáo deste trabalho, foram consultados todos os resumos dos textos submetidos ao GT i8, no período mencionado, totalizando 32 produçôes e, a partir disso, foi feita leitura na íntegra dos trabalhos considerados com potencial para esta pesquisa.

Alguns dos dados aqui apresentados foram levantados através de um trabalho conjunto com o grupo responsável pelo projeto de pesquisa "Formação Continuada de Professores da EJA (educação de jovens e adultos): uma análise do impacto do programa 'UFOP com a Escola' no 
trabalho de professores da Regiáo dos Inconfidentes”, do Departamento de Educação da Universidade Federal de Ouro Preto.

Os trabalhos denominados Estado da Arte Estado do Conhecimento têm sido recorrentes em várias áreas do conhecimento. $\mathrm{O}$ artigo que ora se apresenta se insere neste tipo de pesquisa dada a sua importância e relevância. Como bem salientam Romanowski e Ens (2006, p. 39), ao se referirem aos Estados da Arte em Educação, as pesquisas deste tipo significam

[...] uma contribuiçáo importante do campo teórico de uma área de conhecimento, pois procuram identificar aportes significativos da construção da teoria e prática pedagógica, apontar as restriçóes sobre o campo em que se move a pesquisa, as suas lacunas de disseminação, identificar experiências inovadoras que apontem alternativas de solução para os problemas da prática e reconhecer as contribuiçôes da pesquisa na constituição de propostas na área focalizada.

Essas autoras fazem uma distinção entre Estado da Arte e Estado do Conhecimento, caracterizando o primeiro como um levantamento amplo das publicaçôes acerca de determinada temática, tendo uma diversidade de fontes de pesquisa. Já o Estado do Conhecimento abrange apenas um setor de publicaçóes acerca de determinada temática (ROMANOWSKI; ENS, 2006, p. 40). Partindo desta conceituação, o presente trabalho pode ser caracterizado como um Estado do Conhecimento, por priorizar apenas um setor de publicaçóes, que é o GT i8 da Anped.

Acredita-se que o levantamento e análises que serão apresentados neste artigo constituirá uma fonte importante de dados para os pesquisadores em Educação, especialmente àqueles que se debruçam sobre as temáticas políticas públicas e educação de jovens e adultos.

Este texto está dividido em quatro partes. A princípio, será apresentado um breve histórico da EJA no Brasil, a fim de se fazer uma contextualização. A seguir, será feita uma incursão em algumas pesquisas do tipo Estado de Arte e Estado do Conhecimento, que trabalham temática similar a desta pesquisa. Continuaremos com o levantamento e análises das pesquisas nos anos de $201 \mathrm{I}$ e 2012 e tentaremos, como conclusão, apresentar algumas consideraçóes finais. 


\section{Breve histórico da EJA no Brasil}

Os estudos voltados para a educação de jovens e adultos se ampliaram nos últimos anos e têm estado na pauta de muitas discussóes no campo da política educacional. É importante, ao se fazer uma discussão sobre educação de jovens e adultos no Brasil, relembrar alguns marcos legais que culminaram na educação como um direito de todos. A Constituição de I988, em seu artigo 205, afirma que a educação é "direito de todos e dever do Estado e da família". No artigo 208, temos que "O dever do Estado para com a educação será efetivado mediante a garantia de: I - ensino fundamental, obrigatório e gratuito, inclusive para os que a ele não tiveram acesso na idade própria” (BRASIL, 1988, p. I38).

A Lei de Diretrizes e Bases da Educação, Lei n. ${ }^{0}$ 9.394/96, avança neste sentido, regulamentando a Educação de Jovens e Adultos, ao estabelecer, em seu artigo $2^{\circ}$ :

A educação, dever da família e do Estado, inspirada nos princípios de liberdade e nos ideais de solidariedade humana, tem por finalidade o pleno desenvolvimento do educando, seu preparo para o exercício da cidadania e sua qualificação para o trabalho.

No artigo 37 da referida lei, temos que "A educação de jovens e adultos será destinada àqueles que não tiveram acesso ou continuidade de estudos no ensino fundamental e médio na idade própria” e, ainda, no parágrafo $3^{\circ}$, que "A educação de jovens e adultos deverá articularse, preferencialmente, com a educação profissional” (BRASIL, I996).

Posteriormente, no Parecer do Conselho Nacional de Educação, CNE n. ${ }^{\circ}$ II/200o, são instituídas as diretrizes curriculares nacionais para a Educação de Jovens e Adultos. Este documento expressa o conceito, fundamentos e funçôes da EJA, explicitando as bases legais para a educação de jovens e adultos, definindo os cursos e exames da educação de jovens e adultos e apresentando algumas reflexóes sobre a formação docente para o trabalho com este público (BRASIL, 200o). 


\section{Revisitando alguns estudos}

Algumas pesquisas foram empreendidas com o intuito de mapear as políticas públicas para educação de jovens e adultos no Brasil. Dentre elas, apresentaremos as de Ventura (2008), Santos e Viana (201 I) e Araújo e Jardilino (20II).

Ventura (2008) apresentou uma reflexáo acerca das políticas para a educação de jovens e adultos no Brasil, a partir do GT I8 da Anped, fazendo um levantamento dos trabalhos que contemplam tal temática, no período compreendido entre 1998 e 2008 . A autora observou, nos trabalhos de tal período, que

[...] a maioria das pesquisas desenvolve estudos de caso e sistematizaçóes de experiências de abrangência reduzida; [...] poucos são os estudos sobre financiamento [...] [e ainda] são poucos os estudos sobre EJA tal como ocorre nas redes públicas de ensino (VENTURA, 2008, p. II).

Constatou ainda que grande parte das pesquisas demonstra iniciativas da EJA a partir da segunda metade dos anos de 1990, identifica várias pesquisas que analisam criticamente as políticas do governo Fernando Henrique Cardoso e constata o silenciamento ou inexistência de pesquisas que abordem as políticas no governo Lula (2003-2006). Além dessa lacuna, a autora identificou outras, como a inexistência de trabalhos com as seguintes abordagens:

[...] análises críticas sobre a atuação das ONGs na EJA pós regime autoritário civil-militar; [...] estudos relativos às influências dos organismos internacionais e à repercussão desta influência nas estratégias do MEC para o atendimento da demanda por EJA [...] [e ainda] trabalhos históricos que sistematizem modelos e tipologias da educação de adultos no Brasil e seus pressupostos teórico-filosóficos (VENTURA, 2008, p. I2).

Santos e Viana (20I I) objetivaram também fazer uma pesquisa do tipo Estado da Arte, tendo como fonte de dados a Anped, na categoria EJA 
como políticas públicas, no período de 1998 a 2008. Foram identificados, nos trabalhos analisados por tal pesquisa, as políticas, programas e projetos relacionados à educação de jovens e adultos. Os autores apresentaram os estudos por região, sendo que a região Norte não registrou nenhuma pesquisa; as regióes Nordeste e Sul com 9,52\% cada; a região Centro-Oeste com $\mathrm{I}_{4,2}, 2 \%$ e a região Sudeste com a grande maioria das pesquisas, na ordem de 66,67\%. Identificaram, também, com este estudo, os tipos de pesquisas realizadas, sendo $66 \%$ de abordagem quantitativa/qualitativa, $29 \%$ de abordagem qualitativa e $5 \%$ de quantitativa.

As temáticas enfatizadas em tais pesquisas contemplaram

[...] a descentralização das políticas públicas, a relação entre poder público e sociedade civil, programas de alfabetização e demais propostas de políticas, o distanciamento do Estado ante a EJA, a construção de sentidos no cerne dessa modalidade educacional, bem como a sua situação nas cidades e no campo (SANTOS; VIANA, 20II, p. IO9).

As autoras concluíram este trabalho afirmando a necessidade de que pesquisas sejam feitas em alguns estados importantes, como Bahia, Pernambuco, Paraná e Santa Catarina e ainda que “[...] há muito por se construir em relação à Educação de Jovens e Adultos como direito básico para homens e mulheres" (SANTOS; VIANA, 20I I, p. IIo).

Araújo e Jardilino (20II) analisaram pesquisas relacionadas à educação de jovens e adultos referentes às políticas, sujeitos e práticas pedagógicas. Este trabalho tratou de um balanço da produção sobre a temática, entre os anos de 2006 e 20I0, a partir do GT i 8 da Anped e dos artigos publicados pela Revista Brasileira de Educação, Revista Educação e Sociedade e Cadernos de Pesquisa. Ao todo, foram analisados 82 trabalhos, nas três categorias já informadas anteriormente. Quanto à categoria "políticas públicas para a EJA", os autores identificaram I4 artigos, abordando as seguintes temáticas: políticas internacionais (relacionadas principalmente à VI Confintea); às políticas locais (ampliação da EJA, financiamento); presença das ONGs e do Sistema S (Sesc, Senai e Sesi) na oferta de EJA e um trabalho sobre as políticas para EJA no Plano Nacional de Educação. Com relação aos dados obtidos a partir do GT I8 da Anped, os autores 
identificaram 26 produçóes, abordando alguns programas, como o Proeja, Pronera e Projovem; estudos sobre a EJA no sistema prisional e em áreas de assentamento; e ainda um trabalho sobre as Diretrizes para a EJA, no que se refere aos aspectos operacionais.

Comparando a quantidade de pesquisas em cada categoria definida, os autores perceberam que a categoria "políticas públicas para a EJA" foi a mais recorrente entre as publicaçóes e concluem que esta tendência demonstra a preocupação dos estudiosos na EJA com este aspecto.

Este breve panorama apresentado a partir das pesquisas de Ventura (2008), Santos e Viana (20I I) e Araújo e Jardilino (20I I) servem de plano de fundo para a pesquisa que ora se apresenta, já que indica o estado do conhecimento, bem como as tendências e oportunidades de novas investigaçóes no campo das políticas para a Educação de Jovens e Adultos.

\section{As pesquisas sobre políticas para a EJA nos anos de 2011 e 2012}

Esta pesquisa foi pensada com a finalidade de dar continuidade aos levantamentos e análises feitos sobre políticas públicas para a EJA nos últimos anos, focalizando os trabalhos apresentadas no GT i 8 da Anped, nos anos de 201 I e 2012.

Como procedimentos metodológicos, primeiramente foram selecionados todos os resumos do GT i8 no período mencionado, totalizando 32 produçôes, sendo 16 por ano. Procurou-se fazer uma categorização destas pesquisas a partir de tal leitura e das palavras-chave apresentadas pelos autores. Com relação às pesquisas consideradas como potenciais para esta pesquisa foram feitas leituras na íntegra, a fim de conhecê-las mais profundamente e fazer análises quanto à temática, metodologia, objetivos e conclusóes.

No GT I 8 da Anped, no ano de 20II, dos I6 trabalhos apresentados, 4 trataram especificamente das políticas para EJA (Garcia e Alves; Hypolito e Ivo; Henrique, Baracho e Silva; Furtado e Lima).

Garcia e Alves (20II) investigaram a implantação do Proeja em uma rede estadual de ensino e, nesta, foi observada uma distância entre a implantação e a real efetivação do Programa. A partir dessa constatação, as autoras defenderam a importância e necessidade do Proeja ser efetivamen- 
te realizado, enquanto um programa que amplia o direito à educação às pessoas que historicamente tiveram este direito negado. Defendem ainda o Proeja na perspectiva de ampliar a escolaridade dos alunos e lhes possibilitar a qualificação profissional. Adotou-se nesta pesquisa uma abordagem qualitativa, utilizando como instrumentos a análise documental e entrevistas semiestruturadas.

Outro trabalho que também aborda o Proeja é o de Hypólito e Ivo (20II). Neste, é discutida a adesáo/resistência dos professores de uma Escola Federal de Ensino Técnico agrícola, o Conjunto Agrotécnico Visconde da Graça, campi da Universidade Federal de Pelotas, diante da implantaçáo do Proeja. Os autores apresentaram um estudo sobre os antecedentes históricos no embate travado entre educação profissional, técnica, versus educaçáo integral e conceberam o Proeja, a partir do texto-base que o fundamenta, como

[...] uma política inédita no Brasil, que traz diversas inovaçóes nas reflexóes e discussóes até então realizadas acerca da EJA, além de estabelecer princípios e concepçôes para esta modalidade de ensino, que confrontam o tipo de formação técnica e profissional que até então vinha sendo desenvolvida (HYPÓLITO; IVO, 20II, p. 7-8).

Os autores concluíram que os processos de resistência dos professores são consequência de uma série de fatores, podendo ser destacados: “[...] as representaçôes dos professores acerca do aluno da EJA; a falta de conhecimento sobre a EJA, as dificuldades em definir estratégicas pedagógicas para este público, dentre outras" (HYPÓLITO; IVO, 20II, p. II). No entanto, os autores perceberam que esta resistência por parte dos professores tende a diminuir, na medida em que estes profissionais conheçam e se envolvam mais com o Programa. Esta pesquisa, de abordagem qualitativa, utilizou como instrumentos a análise de documentos e entrevistas.

Henrique, Baracho e Silva (20I I) tiveram como foco de sua pesquisa a percepção de professores e alunos participantes do Proeja, oferecido pelo IFRN nos campi de Natal Zona Norte, Mossoró, Ipanguaçu e Currais Novos, sobre quais práticas pedagógicas contribuíam para a integração do currículo. A partir da identificação de quais eram essas práticas pedagógi- 
cas (trabalhos interdisciplinares, aulas de campo, visitas técnicas, projetos de pesquisa e extensão), as mesmas foram estudadas e chegou-se à conclusão de que elas não acontecem de maneira sistemática e intencional, o que compromete a efetivação de um currículo integrado. A pesquisa foi do tipo qualitativa, de caráter exploratório, tendo como principais instrumentos questionários e entrevistas semiestruturadas.

Furtado e Lima (20I I) apresentaram como objetivo de sua pesquisa favorecer reflexôes sobre a relação entre trabalho e educação para a formação profissional, tendo como foco, o Proeja. Investigaram, para isso, o "currículo em açãa" dos cursos do Proeja em dois Institutos Federais de Educação, Ciência e Tecnologia. Eles observaram certa resistência dos professores quanto à docência na EJA e identificaram dificuldades, como a heterogeneidade e os ritmos de aprendizagem dos alunos, integração dos conteúdos do ensino médio com os do ensino profissional, dentre outros.

Mesmo diante dessas dificuldades apresentadas pelos professores, que se traduziu em resistência, a pesquisa concluiu que a efetivação do Proeja em tais institutos possibilitou um processo de reflexáo dos professores em relação às suas práticas pedagógicas e evidenciou a necessidade de uma formação pedagógica inicial para os docentes que atuam na EJA, dada as especificidades desta modalidade de ensino. Outra preocupação apontada pela pesquisa foi a dificuldade dos professores em associarem teoria e prática. No entanto, apesar de todos esses obstáculos, os docentes manifestam o desejo de realizarem seu trabalho de maneira mais contextualizada, crítica e que atenda às necessidades de seus alunos. Esta investigação foi do tipo qualitativa, participativa/colaborativa, utilizando-se a pesquisa etnográfica. Os instrumentos de coleta de dados foram: observação, entrevistas, fragmentos de histórias de vida, dinâmicas grupais e grupo focal.

Para visualizar os dados coletados no ano de 201 I, o gráfico I representa a porcentagem de trabalhos apresentados no GT i8 da Anped, que tratam a temática políticas públicas para a EJA (25\%) e a porcentagem dos demais trabalhos, no mesmo GT, com outras temáticas (75\%). As outras temáticas se referem à formação docente para EJA, práticas pedagógicas, sujeitos da EJA (professores e alunos), EJA e educação especial.

O gráfico 2 representa a porcentagem de trabalhos apresentados no GT I8 da Anped, no ano de 20II, identificados por região. Percebemos que a regiáo Nordeste concentra a maioria das publicaçóes $(37,50 \%)$, se- 
guida pelas regióes Sul e Sudeste (25\% cada) e pela região Centro-Oeste (I2,5\%). Neste ano, não houve nenhuma publicação da região Norte.

\section{ANPED 2011 - Temáticas abordadas no GT 18}

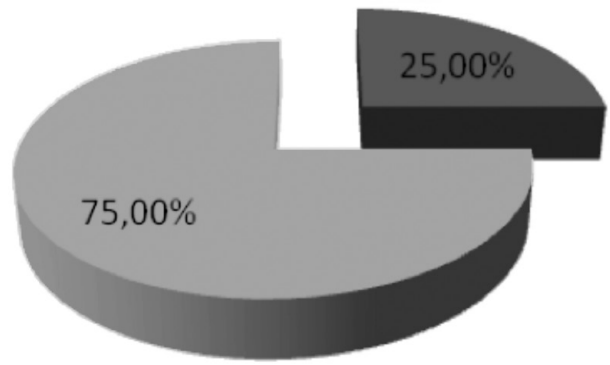

Políticas Públicas para EJA = Outras Temáticas

Gráfico 1: Temáticas abordadas GT 18 ANPED, 2011

\section{ANPED 2011 - Localização geográfica das produções}
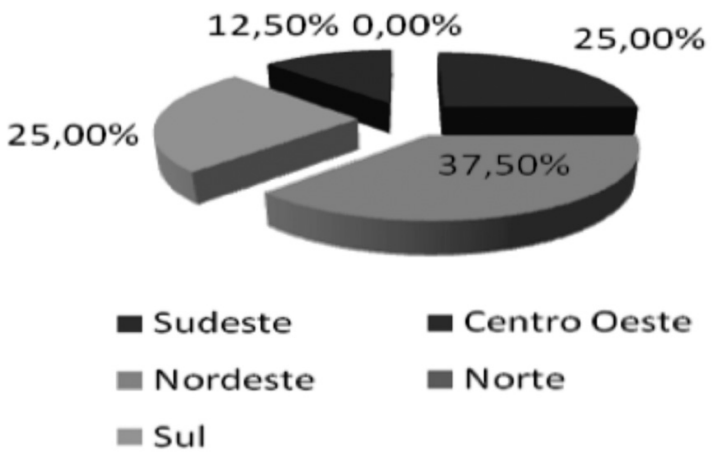

- Centro Oeste

Norte

- Sul

Gráfico 2: Localização geográfica das produções - ANPED, 2011

No ano de 20I2, dos I6 trabalhos apresentados no GT I8, seis se referem às políticas para EJA (Di Pierro; Carvalho; Silva, Diniz e Baracho; Silva; Ferreira, Scopel, Oliveira e Amparo; Machado e Garcia). 
Carvalho (2012) expressou em seu trabalho, fruto de uma pesquisa de doutorado, as contradiçóes e incongruências das políticas para a educação de jovens e adultos (EJA) no Brasil no período de governo do presidente Luiz Inácio Lula da Silva, nos anos de 2003 a 2006 e de 2007 a 20I0, caracterizando-as como políticas de "coalizão" e "contradição". Foram analisados alguns programas, projetos e políticas relacionados à EJA, como o Programa Brasil Alfabetizado, o ProJovem, a criação da Secretaria de Educação Continuada, Alfabetização e Diversidade (Secad). Procurou-se perceber também o impacto do Fundo de Manutenção e Desenvolvimento da Educação Básica e de Valorização dos Profissionais da Educação (Fundeb) na EJA.

A pesquisa concluiu que tais políticas, embora tenham representado certo avanço no cenário da EJA no Brasil, não conseguiram reverter o quadro de marginalização histórica em que esta modalidade de ensino se insere. Quanto aos investimentos federais para as políticas da EJA, percebeu-se que houve maior responsabilização da União; no entanto, os resultados alcançados não foram satisfatórios, diante das reais demandas de investimentos. A autora concluiu, ainda, a necessidade de se "lutar" para superar os problemas da EJA, através dos fóruns, conselhos, comissóes legislativas, dentre outras entidades.

Silva (2OI2) analisou o processo de implantação e os desafios enfrentados na consolidação do Proeja no Instituto Federal de Santa Catarina (IF-SC), nos seus diferentes campi. Percebeu-se nesta investigação que, na consolidação do Proeja, predominaram ações transitórias e desarticuladas e que os principais desafios se referiram à formação docente, à sistematização das experiências, às práticas pedagógicas que precisam ser integradas, buscando, dentre outros aspectos, a definição de estratégias adequadas ao público da EJA. A pesquisa chamou atenção ainda para a necessidade de um trabalho em conjunto, engajado, de todos os agentes envolvidos com a EJA a fim de que mudanças necessárias aconteçam.

Silva, Diniz e Baracho (2012) objetivaram, com sua pesquisa, analisar a efetivação do Proeja, em um curso de alimentos, do Instituto Federal de Educação, Ciência e Tecnologia do Rio Grande do Norte (IFRN), no campus Currais Novos, identificando a sua contribuição para a formação integral dos jovens e adultos atendidos naquela localidade; formaçáo esta embasada em três pilares: formação geral, formação profissional e desenvolvimento lo- 
cal. Esperava-se constatar se as metas definidas pelo governo federal, a partir do Proeja, estáo sendo alcançadas. A partir dos dados analisados, concluiu-se que o Proeja, com suas metas e açóes, atende às necessidades e características da região, contribuindo significativamente para o desenvolvimento local e, consequentemente, com as condiçôes de vida da população.

Ferreira, Scopel, Oliveira e Amparo (20I2) analisaram a formação dos alunos do Proeja do Instituto Federal do Espírito Santo, por meio do Projeto Integrador. O Projeto Integrador foi uma experiência diferenciada, na qual os alunos e professores, a partir de suas vivências, experiências e saberes, definiram a estrutura curricular do curso, algo que difere da estrutura do Proeja. A pesquisa elucidou as contribuiçóes de tal projeto, principalmente no que diz respeito à prática pedagógica, à integração do currículo e à valorizaçáo e visibilidade dos sujeitos da EJA. Esta pesquisa, de abordagem qualitativa, foi realizada por meio de uma pesquisa-ação.

Machado e Garcia (2012) buscaram compreender as relaçōes existentes entre a Educação de Jovens e Adultos e a Educação Profissional, através de dois programas federais: o Programa Intensivo de Preparação da Mão-de-Obra (Pipmo), desenvolvido no Brasil nos anos de 1960, na época da Ditadura Militar e um mais atual, o Programa Nacional de Acesso ao Ensino Técnico e Emprego (Pronatec). Para se fazer esta análise, o referido trabalho fez incursóes na história da EJA e identificou relaçôes muito próximas, entre o passado e o presente, concluindo que há muito ainda a se caminhar para a garantia de uma educação como direito e para uma formação profissional mais ampla, que não contemple somente aspectos técnicos, mas sim uma formação humana integral.

Di Pierro (2012) apresentou uma pesquisa em andamento e, portanto, com resultados preliminares, em que procurou analisar "[...] a colaboraçáo entre as esferas do governo nas políticas públicas para a educação de jovens e adultos (EJA) no Estado de São Paulo". Ela trabalhou com I28 municípios paulistas, no período de 2005 a 20I0, discutindo o papel regulador do Estado na implementação das políticas sociais e das políticas públicas para a EJA e a importância do Fundeb, constatando que os valores estabelecidos por tal fundo não são utilizados de maneira devida nas despesas municipais. Os dados revelaram que o Fundeb náo ampliou e qualificou a oferta de EJA em tais municípios, mas, ao contrário, houve declínio nas matrículas. Os resultados preliminares de tal estudo demonstraram 
[...] isolamento e heterogeneidade dos municípios, cuja capacidade financeira, administrativa e pedagógica é muito desigual; fragmentação de políticas e programas; competição políticoeleitoral entre os governos das três instâncias; falta de mecanismos efetivos de redistribuição e coordenação entre elas. (DI PIERRO, 20I2, p. I5).

Quanto à metodologia, houve na primeira etapa da pesquisa uma análise quantitativa e, posteriormente, estudos de caso, metodologia ainda em desenvolvimento na época da publicação desta.

O gráfico 3 representa a porcentagem de trabalhos apresentados no GT I8 da Anped, ano de 20I2, que trataram da temática políticas públicas para a EJA (37,5\%) e a porcentagem dos demais trabalhos, no mesmo GT, com outras temáticas $(62,5 \%)$. Nestas outras temáticas foram encontrados trabalhos que abordaram: identidade docente, representaçóes sociais, idosos e tecnologia, práticas de letramento, livro didático, estado da arte, sujeitos da EJA.

O gráfico 4 representa a porcentagem de trabalhos apresentados no GT I 8 da Anped, ano de 20I2, por região. A região que mais apresentou trabalhos foi a regiáo Sudeste $(37,50 \%)$, seguida da região Nordeste, com 31,25\%. A região Centro-Oeste participou com I $8,75 \%$ das produçóes e a regiáo Norte com um trabalho, que corresponde a $6,25 \%$ da produção total.

\section{Consideraçóes finais}

A partir dos trabalhos apresentados, percebem-se algumas continuidades no que foi constatado nas pesquisas anteriores, como também algumas alteraçôes. Ventura (2008) chama a atenção para o número reduzido de pesquisas apresentadas na Anped, GT I8, que trataram do financiamento da educação de jovens e adultos. Observou-se que este dado permaneceu, já que no ano de 20 I I não houve nenhuma pesquisa com tal abordagem e, em 20I2, apenas duas pesquisas abordaram tal temática: Carvalho (20I2) e Di Pierro (20I2). 


\section{ANPED 2012- Temáticas abordadas no GT 18}

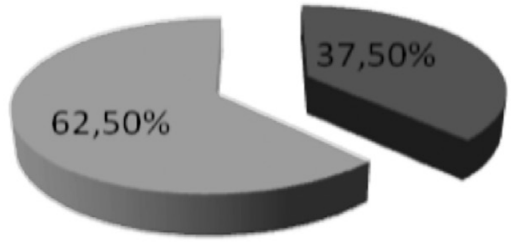

Políticas Públicas para EJA E Outras Temáticas

Gráfico 3: Temáticas abordadas no GT 18 - ANPED, 2011

\section{ANPED 2012 - Localização geográfica das produções}
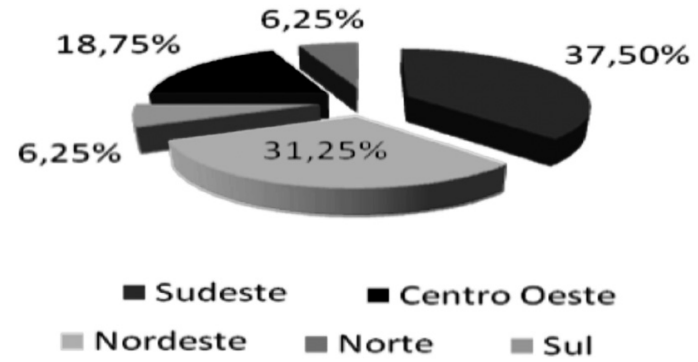

Gráfico 4: Localização geográficas das produçôes - ANPED 2012

Percebeu-se também uma continuidade quanto ao aumento da quantidade de produçóes sobre os programas federais para a EJA, especialmente o Proeja, como já salientava Araújo \& Jardilino (20II). Dos I6 trabalhos apresentados pelo GT I8 da Anped, no ano de 20II, quatro se referiram às políticas públicas, sendo que todos eles trataram do Proeja. No ano de 20I2, nesta mesma fonte de dados, dentre os I6 trabalhos apresentados, 6 se referiram às políticas públicas para EJA e, destes, 3 abordaram o Proeja. Vale informar que no ano de 20II, a Anped, em seu GT I8, encomendou um trabalho intitulado "Avaliação da produção das pesquisas sobre o Proeja: impactos da implementação do programa". Embora este artigo náo tenha como foco os trabalhos encomendados, o destaque se dá pela importância atribuída a esta temática na produção acadêmica nos últimos anos. 
Ventura (20II) chama a atenção para a inexistência de pesquisas sobre os programas criados e implementados durante o primeiro mandato do governo Lula (2003-2006). Este dado é alterado nesta nova pesquisa, já que em 2012 o GT I8 apresentou a pesquisa de Carvalho (20I2), que analisou a EJA no governo Lula em seus dois mandatos (2003-2010). No entanto, outras lacunas apresentadas por Ventura permaneceram, sendo elas:

[...] análises críticas sobre a atuação das ONGs na EJA pós-regime autoritário civil-militar; de estudos relativos às influências dos organismos internacionais e à repercussão desta influência nas estratégias do MEC para o atendimento da demanda por EJA; e de trabalhos históricos que sistematizem modelos ou tipologias da educação de adultos no Brasil e seus pressupostos teórico-filosóficos (VENTURA, 20I I, p. I2).

Santos e Viana (20II), no período de 1998 a 2008, bem como Araújo e Jardilino (20II), no período de 2006 a 20Io, não encontraram nenhum trabalho produzido na região Norte do país. Mesmo que de forma tímida, este quadro sofre alteraçóes, já que no ano de 2012 foi apresentado um trabalho desta região no GT i 8 da Anped.

As pesquisas apresentadas no GT I 8 da Anped, originárias da região Nordeste, têm tido um crescimento considerável. De 9,25\% (SANTOS; VIANA, 20II) nos anos compreendidos entre 1998 e 2008, passou-se, no ano de 2010 , a representar $31,25 \%$ da produção nacional e, em 2012 a $37,50 \%$. Esta tendência ao crescimento das produçôes de tal região já era observada e justificada por Araújo e Jardilino (2OII).

O gráfico 5 representa um comparativo entre os anos de $201 \mathrm{I}$ e 20I2, quanto à localização geográfica das pesquisas apresentadas no GT I 8 da Anped. Destaca-se o crescimento da produção das regióes Nordeste e Sudeste do país.

Observa-se que tem havido, nestes dois últimos anos, um crescimento nas produçôes que contemplam a temática políticas públicas para EJA, como demonstra o gráfico 6. Em 20II, tínhamos uma produção de $25 \%$ de pesquisas que se referiam a esta temática, ao passo que em 20I2, a porcentagem é de $37,5 \%$. 


\section{Percentual de pesquisas, por região}

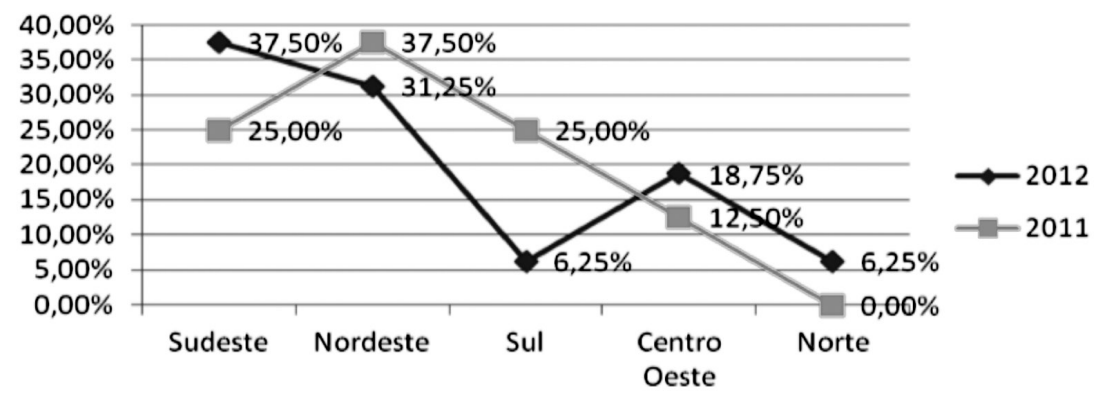

Gráfico 5: Percentual de pesquisas, por regiáo

Tal constatação pode indicar um interesse crescente da academia por compreender, analisar e até mesmo intervir neste meio, buscando melhorias para as políticas de oferta da educação de jovens e adultos em nosso país. Segundo Santos e Viana (apud AZEVEDO, 2004, p. 5), "Quando se enfoca as políticas públicas, significa ter presente as estruturas de poder e de dominação, os conflitos infiltrados por todo tecido social e que têm no Estado o lócus da sua condensação". Daí a importância de pesquisas que analisem criticamente este cenário e busquem contribuir para a efetivação de uma educação verdadeiramente humana, democrática, que valorize o sujeito da EJA (professor e aluno), em sua particularidade e dignidade.

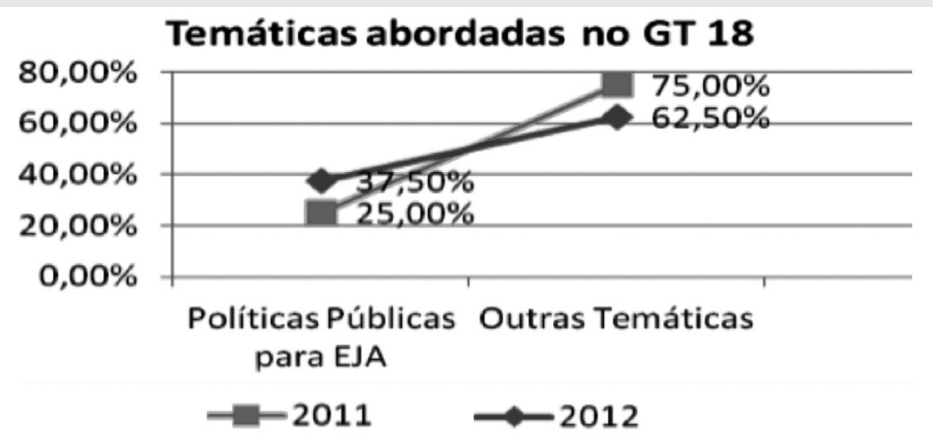

Gráfico 6: Temáticas abordadas no GT 18 
No que se refere à metodologia e procedimentos de pesquisa, percebeu-se, a partir dos dados coletados nos trabalhos, que a grande maioria optou pela pesquisa qualitativa, tendo-se utilizado, em grande parte, entrevistas, questionários e estudos de caso.

Este trabalho é finalizado esperando ter contribuído, de alguma forma, para a construção do cenário acerca das produçôes sobre políticas públicas para EJA em nosso país e para futuras pesquisas.

\section{Nota}

1 A pesquisa foi realizada no marco do estado da arte da temática para o projeto de pesquisa. "Formaçấo continuada de professores da EJA: uma análise do impacto do Programa "UFOP com a Escola" no trabalho dos professores da Regiāo dos Inconfidentes, realizada no Grupo de Pesquisa Formação e Profissão Docente (Foprofi) 20I2-2013, financiada pela Fapemig e coordenada pelos professores José Rubens Lima Jardilino, Célia Maria F. Nunes, Regina M. B. de Araújo. Uma primeira versão deste texto foi apresentado recentemente pelos autores no XI Congresso Nacional de Educação (Educere), em Curitiba, 23-26 de setembro 2013.

\section{Referências}

ARAÚJO, R. M. B.; JARDILINO, J. R. L. Educação de Jovens e Adultos as políticas, os sujeitos e as práticas pedagógicas: um olhar sobre a produção do campo - 2006 a 20 Io. EccoS-Revista Cientifica, São Paulo, n. 25, p. 59-75, jan./jun. 20I I

AZEVEDO, Janete M. Lins de. A educação como política pública. 3. ed. Campinas: Autores Associados, 2004.

BRASIL. Conselho Nacional de Educação. Câmara de Educação Básica. Resolução CNE/ CEB no. or/200o, de 5 de julho de 2000: Estabelece as Diretrizes Curriculares Nacionais para a Educação de Jovens e Adultos. Diário Oficial da União, Brasília, DF, I9 jul. 2000. Seção I, p. I8.

BRASIL. Constituição Federal (1988). Brasília, DF: Senado, 1988.

BRASIL. Lei de Diretrizes e Bases da Educação - lei 9394, de 20/I2/96. Diário Oficial da União, Brasília, DF, 23 dez. I996. Seção I, p. 27833

CARVALHO, Marcelo Pagliosa. A Educação de Jovens e Adultos nos governos Lula (200320II): incongruências das políticas e do FUNDEB. In: REUNIÃO ANUAL DA ANPED, 35., 20I2, Porto de Galinhas. Anais... Porto de Galinhas: Anped, 20I2. p.I-I8.

DI PIERRO, Maria Clara. A configuração do ensino de jovens e adultos do Estado de São Paulo sob a vigência do FUNDEB: resultados preliminares de uma pesquisa em andamento. In: REUNIÃO ANUAL DA ANPED, 35., 20I2, Porto de Galinhas. Anais... Porto de Galinhas: Anped, 20I2. p.I-I8. 
FERREIRA, M. J. R de; SCOPEL, E. G.; OLIVEIRA, M. de; AMPARO, Z. T. S da. Projeto Integrador: o percurso formativo dos alunos do PROEJA na perspectiva da formação integrada. In: REUNIĀO ANUAL DA ANPED, 35., 20I2, Porto de Galinhas. Anais... Porto de Galinhas: Anped, 20I2. p.I-I6.

FURTADO, E. D. P.; LIMA, K. R. R. EJA Ensino Médio e Educação Profissional: Limites e possibilidades no PROEJA. In: REUNIÃO ANUAL DA ANPED, 34., 20I2, Natal. Anais... Natal: Anped, 20II. p.I-I5.

GARCIA, L. T.; ALVES, M. F. O Proeja em uma rede estadual de ensino: trajetórias de um programa implantado e não realizado. In: REUNIÃO ANUAL DA ANPED, 34., 20I2, Natal. Anais... Natal: Anped, 20I I. p.I-I6.

HENRIQUE, A. L. S.; BARACHO, M. G; SILVA, J. M. N da. Práticas Pedagógicas de Integração no PROEJA-IFRN: o que pensam os professores e estudantes. In: REUNIÁO ANUAL DA ANPED, 34., 20I2, Natal. Anais... Natal: Anped, 20I I. p. I-I8.

HYPOLITO, Á. L. M.; IVO, A. A. Educação, Políticas Públicas e os processos de adesão e resistência à implantação de um curso na modalidade PROEJA. In: REUNIÃO ANUAL DA ANPED, 34., 20I2, Natal. Anais... Natal: Anped, 20I I. p.I-I6.

MACHADO, M. M.; GARCIA, L. Passado e presente na formação de trabalhadores jovens e adultos. In: REUNIÃO ANUAL DA ANPED, 35., 20I2, Porto de Galinhas. Anais... Porto de Galinhas: Anped, 20I2. p.I-I6.

ROMANOWSKI, J. P; ENS, R. T. As pesquisas denominadas do tipo "Estado da Arte" em Educação. Revista Diálogo Educacional, Curitiba, v. 6, n. I9, p. 37-50, set./dez. 2006.

SANTOS, A. R; VIANA, D. Educação de Jovens e Adultos: uma análise das políticas públicas (I998 a 2008). In: SOARES, Leôncio (Org.). Educação de Jovens e Adultos: o que revelam as pesquisas. Belo Horizonte: Autêntica, 20I I. p. 83-II4.

SILVA, A. L. da. O PROEJA do Instituto Federal de Santa Catarina. In: REUNIÃO ANUAL DA ANPED, 35., 20I2, Porto de Galinhas. Anais... Porto de Galinhas: Anped, 20I2. P.I-I7.

SILVA, J. M. da; DINIZ, A. L. P.; BARACHO, M. G. das. O PROEJA no IFRN Campus Currais Novos e o desenvolvimento local: conexôes possíveis. In: REUNIÁO ANUAL DA ANPED, 35., 20I2, Porto de Galinhas. Anais... Porto de Galinhas: Anped, 2OI2. P.I-I6.

VENTURA, Jaqueline. A política educacional para a EJA na produção científica do GT Educação de Pessoas Jovens e Adultas da Anped (1998-2008): contribuiçóes para o debate. In: REUNIÃO ANUAL DA ANPED, 32., 20I2, Caxambu. Anais... Caxambu: Anped, 2008. P.I-I5.

Recebido em I8 out. 2013 / Aprovado em II nov. 2013

Para referenciar este texto

ARAÚJO, R. M. B. et al. Políticas para educação de jovens e adultos no Brasil: a produção da área nos anos de 2011 e 2012 veiculadas na Anped. EccoS, São Paulo, n. 32 , p. 67-84. set/dez. 2013. 